\title{
Erika Trejo, artista mejicana entre la denuncia y la enunciación
}

\section{Erika Trejo, Mexican artist between the complaint and statement}

\author{
Eva Santos SÁnchez-Guzmán \\ Universidad de Murcia. Facultad de Bellas Artes \\ evasanto@um.es
}

Recibido: 8 de enero de 2011

Aprobado: 28 de septiembre de 2011

\begin{abstract}
Resumen
En este artículo se presenta parte de la trayectoria de la artista mexicana Erika Trejo como ejemplo de artista, mujer e inmigrante. Para ello muestro ocho de sus obras y algunas teorías feministas que han influido en sus creaciones. Gracias a la entrevista con ella realizada he podido comprender claramente los vínculos de su trabajo con su propia biografía. Si bien no hablamos de una obra pretendidamente autobiográfica, el hecho de vivir sexuada en femenino ha marcado el sentido de su discurso. Toma como punto de partida la experiencia de las mujeres con la que va relacionándose, el proceso de integración realizado tras su migración y su propia maternidad. El cuerpo en movimiento es su carga de energía creativa, un cuerpo que es el otro ante dos bipolaridades culturales de poder regidas por el hombre occidental.
\end{abstract}

Palabras Clave: Artista, cuerpo, mujer, inmigrante, denuncia, enunciación, feminismo y disfunción del discurso.

Santos Sanchez-Guzmán, E. 2011: Erika Trejo, artista mejicana entre la denuncia y la enunciación. Arte, Individuo y Sociedad, 24(1), 59-75

\begin{abstract}
In this article, part of the history of the Mexican artist Erika Trejo as an example of an artist, woman, immigrant and mother. It looks at eight of his works and some feminist theories that have influenced their creations. Through interview conducted with her I could understand clearly links his work with his own biography. While not speaking of an autobiographical work, the fact of living in a woman's body has addressed the meaning of his speech. She takes as its starting point the experience of women which is related to the integration process after migration made her own motherhood. Body movement is its creative energy, a body that is the one of the two cultural power bipolarities governed by the Western man.
\end{abstract}

Key Words: Artist, women, immigrant, mother, complaint, statement, feminism and speech dysfunction.

Santos Sanchez-Guzmán, E. 2011: Erika Trejo, Mexican artist between the complaint and statement. Arte, Individuo y Sociedad, 24(1), 59-75

Sumario: 1. Introducción, 2. Su equipaje, 3. Su obra, 3.1. La vaquita y Cosas de mujeres, 3.2. Proceso de integración, 3.3. Premio de arquitectura efimera para la construcción de un Peep Show, 3.4. In situ, 3.5. Cruela, 3.6. Plebiscito reproductivo, 3.7. Integración de sabores, 4. Conclusiones. Financiación. Referencias 


\section{Introducción}

Si el arte feminista y los estudios de género se promulgaron desde los años setenta como vehículos primordiales para desestabilizar las estructuras que permitieron la superioridad de un género sobre otro, el arte de la población inmigrante se configura como elemento básico para transgredir las fronteras, físicas y simbólicas, que se dibujan tanto en las sociedades de acogida como en las experiencias de aquellas personas que se sumergen en unos movimientos geográficos, devenidos en geopolíticos, más antiguos que las sociedades patriarcales.

Es así, que la inquietud por hallar, investigar y difundir propuestas artísticas en las que convergen ambas reflexiones, mujer e inmigración, fuera la motivación inicial de este trabajo. Su fin, permitir acceder a nuevas posibilidades de acción y pensamiento que perturben el universo simbólico que ha justificado tales relaciones de poder. $\mathrm{Si}$ para la feminista Chandra Talpade Mohaty el

trabajo feminista transcultural debía poner atención a las micropolíticas de contexto, subjetividad y lucha, así como a la macropolítica de los sistemas y procesos políticos y económicos globales (2008:413)

Será en la primera dimensión discutida en la que aportaremos el presente análisis, no sin eludir, como ella explica, "que lo particular tiene un significado universal"

Para ello atendemos a las estrategias creativas propuestas por la artista Erika Trejo, nacida en México y residente en España desde hace diez años, con el objetivo de descubrir cómo se vivencia y se representa la lucha por la identidad y la integración de un cuerpo migrado femenino. Aurora Alcaide defendió la idoneidad del video como.

una herramienta muy útil para aquellos artistas comprometidos socialmente y que deseen abordar el tema de las relaciones entre lo local y lo global, o de sus consecuencias más inmediatas, como es la inmigración, desde la perspectiva del tiempo" (2011)

Para defender esta teoría la autora se valió, entre otras, de algunas de las obras de la artista que ahora analizamos. Sin embargo, veremos que el performance, arma de lucha desde las primeras generaciones de artistas feministas, será adoptado por Erika como otra posibilidad, ya que el cuerpo se hace viviente y el espacio de la representación experiencial, promoviendo de este modo el encuentro de subjetividades.

Ante este encuentro ¿dónde situarnos para llevar a cabo nuestro propósito? ¿Es posible escribir objetivamente de performance feministas desde un cuerpo también sexuado en femenino? Y geográficamente ¿dónde nos ubicamos, si es posible este término estático, para analizar una experiencia migratoria no vivenciada perteneciendo a un país de acogida, o, deberíamos decir, a la cultura académico-hegemónica? Por ello ha sido necesario establecer una estructura de análisis abierta y permeable, en la cual la teoría y la experiencia, la objetividad y subjetividad, la incertidumbre y seguridad se han trenzado entre ambas orillas.

Esta metodología se ha enriquecido con la conversación que realizamos con la artista antes del comienzo de las vacaciones escolares. En aquellos meses, Erika 
había estado preparando su trabajo Confusiones de Mujeres, una pieza de teatro en la que, a través de un diálogo con el pueblo, revisa la violencia de género que se produce en el ámbito doméstico como reflejo de las estructuras de poder del patriarcado. Se complacía por haber tenido la ocasión de dirigir una creación colectiva con actrices y actores no profesionales cuyas historias, como ella sugiere, tal vez no estuviesen muy alejadas de las de sus personajes. Esta adaptación de Si los tiburones fueran hombres de Bertolt Brecht, le permitía tomar la realidad femenina como arma política del mismo modo que el autor germano proponía "una transformación de lo social desde el conocimiento de los hechos, de los símbolos, de la cotidianidad" (Gaspar, 2006)

Al margen de la significación que toma como título de la obra, la expresión "Confusiones de mujeres" nos introduce en la trayectoria de Erika Trejo porque habla de las mujeres y de las teorías feministas, de sus prácticas y luchas en continuo diálogo, de dudas y disputas. Y lo hace también porque nos define cómo una mujer, en su experiencia artística y personal, se acerca y se aleja de los estereotipos, de esos diálogos de poder, de las creencias culturales, viviendo una vida actuada en un cuerpo de mujer. Una joven artista en proceso que va descubriendo un modo creativo entre la denuncia y la enunciación como principios para la subversión. Me propongo adentrarles en su discurso, exponiendo algunos de sus trabajos más performativos, comentados por ella misma, y remitiéndolos a posibles referencias conceptuales.

\section{Su equipaje}

Erika Trejo nació en México DF en 1976. Desde su propio ámbito familiar percibió la condición femenina como subordinación. Levantando la mirada más allá, pudo observar que la mujer en la sociedad mexicana es intimidada por todo, vive con miedo al asesinato y a la violación. Su cuerpo, nuestro sexo, impunemente puede ser agredido. La violencia se haya también en la invisibilidad impuesta en las representaciones de género, como señala Araceli Barbosa, "el ocultamiento de las identidades individuales de las mujeres constituye el producto de los efectos negativos de la discursividad hegemónica" (2008:25)

Las experiencias de las mujeres con las que la artista ha ido relacionándose se mezclan con sus vivencias cotidianas para obtener el componente conceptual de su trabajo. Un ingrediente amargo que adquirió como una necesidad para hablar de él, para visibilizar cada una de esas identidades ocultas, y que importó consigo en su viaje migratorio.

Se formó en el Laboratorio de Teatro Campesino e Indígena de México dirigido por María Alicia Martínez Medrano. El teatro con estas comunidades persigue un cambio de actitud ante lo que de peyorativo puede tener el concepto de indígena para el colono, el habitante de la ciudad o los poderes políticos. La improvisación se convierte en la herramienta básica para que los nativos puedan representar obras de Federico García Lorca, Elena Garro... En el Laboratorio aprendió que el teatro no es llevar espectáculos a los pueblos, sino dramatizar con la población misma. Comprenderá que el trabajo debe partir de los propios grupos de mujeres, porque este es el lugar para acceder a la experiencia y análisis de la realidad y su contexto. 
Si atendemos a los autores Blancarte, González y Casillas en su texto La influencia de las religiones cristinas, podríamos entender una relación entre estas prácticas expresivas y una actuación popular que se sitúa entre el ritual y la procesión cristiana (1993:548). De este modo, el teatro en la calle toma su significación del ritual, tanto el de la vida popular mexicana que tiene este tipo de respuestas para las diversas crisis y desafíos de la vida, como el de la práctica de las procesiones llevada a cabo por el catolicismo, en las que la representación del culto se traslada del interior a la calle y el pueblo asume la actuación religiosa.

Completa su formación en la UNAM con el profesor David Psalmon. Con él aprendió otra forma de actuar: la acción directa en la calle. Trabajaron en los mercados y establecieron un diálogo con los zapatistas sobre la influencia gringa y sobre cómo trataban a sus mujeres. La interpretación del personaje de Adela, en la Casa de Bernarda Alba, de Federico García Lorca, supuso definitivamente su tendencia hacia las teorías feministas que marcarán sus prácticas artísticas.

La articulación plástica de su discurso ideológico se define a partir del arte feminista mexicano de los ochenta. Una de las artistas más influyentes de ese movimiento sería Mónica Mayer, cuyo taller de arte feminista, impartido entre 1983 y 1984 en la Academia de San Carlos, fue determinante para el desarrollo de un arte de género en México. De aquí surgieron grupos como Tlacuilas y Retrateras o Polvo de Gallina Negra cuyas obras pretendieron como afirma Raquel Tibol en relación a éste último grupo, "adquirir mayor conciencia sobre los mecanismos psíquicos y funcionales del ser femenino" (Barbosa, 2008:122)

Con este equipaje Erika Trejo viaja a Madrid donde interpreta pequeños papeles teatrales. Al año de su estancia en la capital española, decide junto a su familia desplazarse a Murcia.

\section{Su obra}

\subsection{La vaquita y Cosas de mujeres}

En 2005 las "Hermanas mexicanas" (Erika y Cyntia) fueron seleccionadas en el Primer Festival Alterarte 05 con dos performance para representar en el Mercado Saavedra Fajardo: La Vaquita (figura 1) y Cosas de mujeres (figura 2)

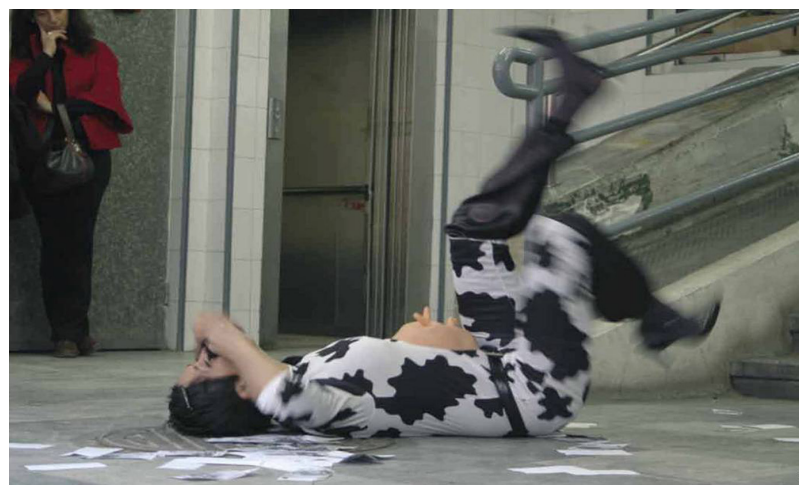


Descontextualizaron un espacio visitado principalmente por mujeres, cuya ocupación son "sus labores" en el ámbito doméstico. Es la otra mirada la invitada al evento.

Siempre estaré unida al teatro, pero seguir los guiones y las pautas que se marcan... creo que el público hoy en día necesita otro tipo de recepción de la obra, de los mensajes artísticos y creo que el performance cumple con eso, señala Erika.

Estos trabajos hallan su base en el teatro en la calle, en la acción improvisada que aprendió en México y en las experiencias vividas como mujer. Performance que, en palabras de Hubert Besalier

consiste menos en copiar o en representar la realidad que en captar sus fuerzas y en revelarlas, en hacer sensibles en si mismos el tiempo y la duración de las cosas, en explicar la tensión que recubren lo banal y lo cotidiano. (1993:134)

Si antes comentábamos la cercanía del teatro en la calle con los rituales populares y procesiones cristianas, no podíamos pasar por alto otros actos históricos que resultan imprescindibles al hablar de la performance feminista, son los modos de conquista del espacio público por parte de las sufragistas. Para Amelia Valcárcel ellas inauguraron nuevas formas de protesta como las manifestaciones, la huelga de hambre o el autoencadenamiento. (Herrera, 2011:142)

La Vaquita es la metáfora del cuerpo de mujer útil, usado al antojo del que posee los medios productivos.

Hay vaquitas en todas las culturas. Era la institucionalización del cuerpo de la mujer, un cuerpo para el placer, un cuerpo para tocar, un cuerpo para poseer. Una vaquita que pasaba por los rituales señalados para dicha institucionalización, asevera Erika.

Tanto el disfraz como los movimientos exacerbados con los que se movían las autoras ante la puerta del mercado, dotaban al performance del tono irónico que ha caracterizado las acciones feministas mexicanas. En este sentido podemos citar la compleja actuación del grupo Tlacuilas y Retrateras, La fiesta de quince años, celebrada en 1984 en la Academia de San Carlos, en la que desmitificaron la tradición por la cual se

exhibe a la mujer casadera (...) para que sea elegida -presentación en sociedadcomo una mercancía de consumo para el mejor postor que la demande en matrimonio. (Barbosa, 2008:110) 


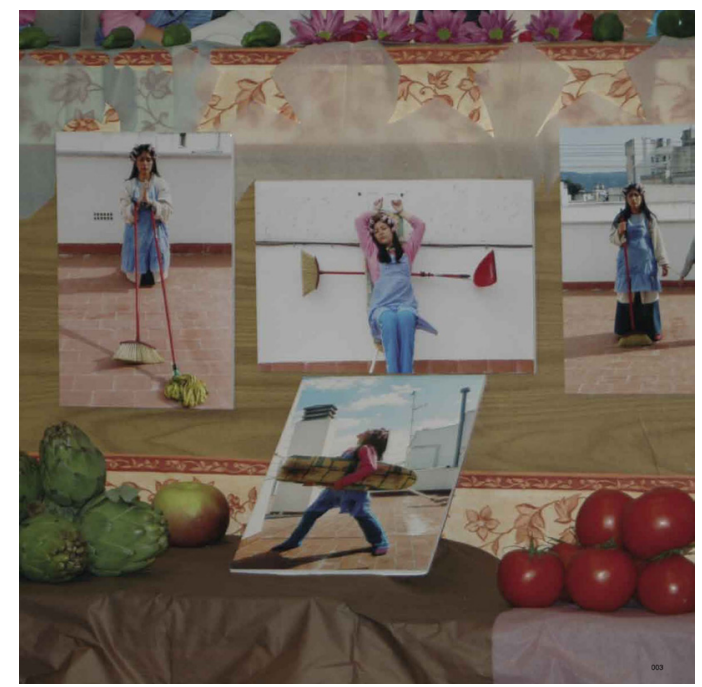

Figura 2. Cosas de mujeres, 2005. (Imagen publicada en el Catálogo Alterarte 05)

Si La Vaquita alude a la desposesión del cuerpo de la mujer en manos de la institución en Cosas de mujeres, Las hermanas mexicanas cuestionan su tiempo. Un tiempo dedicado al otro, a su cuidado, a su alimentación, a su atención, y siempre con plena disposición. En el mercado levantan un chiringuito improvisado.

Las mujeres llegan y ven la fruta, la verdura, y quieren comprar. Al levantar la mercancía se encuentran con las foto-acciones. Las dejamos verlas, y a continuación hablamos sobre las fotos intentando establecer un diálogo con ell@s acerca de las situaciones que están viendo, explican en el catálogo Alterarte 05.

Las fotografías nos relatan acciones en la azotea de un edificio ubicado en cualquier lugar geográfico, situaciones de sumisión de una mujer, con rulos y delantal, ante las tareas del hogar: la plancha, la fregona, el recogedor... La ridiculización que adquieren dichas tareas en las imágenes no puede sino doler a aquellas que las defendemos como labores dignas y necesarias, si bien admitimos la oportunidad de estas posturas críticas para sacudir algunas conciencias.

\subsection{Proceso de integración}

¿Cómo obtiene su posición Erika Trejo en este complejo entramado en el que posee dos condicionantes peyorativos: mujer e inmigrante? Proceso de integración (Festival Alterarte 07) (figura 3) es un videoperformance en el que, ante una proyección que reproduce una acción similar a la actuada in situ, la autora va tomando el papel de una mujer inmigrante, que asume los estereotipos de la mujer occidental como medio de integración en la sociedad de acogida. Ésta, una vez llegada a nuestro país 
realiza una parcial lectura de nosotras y sólo persigue las actitudes consumistas. De este modo, la acción consiste en hacerse forrar con publicidad de Media Mark, ponerse una peluca y adornase con un collar de perlas. Concluye con una gran carcajada ante el público de un locutorio. Cree así que ha cumplido con las pautas consumistas de esta nueva sociedad a la que desea integrase. "La acción comienza con medio torso desnudo a la manera que las indias estaban cuando llegaron los colonizadores y cómo se va occidentalizando" apunta Erika.

Estas acciones (la proyección y la performance) se superponen temporalmente creando una disfunción del discurso. Como señala Anna María Guash, para W. Benjamín las discontinuidades del montaje trastocan lo real, y desmontan la continuidad narrativa "permitiendo establecer nuevas relaciones entre arte y política" (2000:472) porque ofrecen un modo, o modos múltiples, de aproximación a esta realidad y con ello nos invita a una lectura crítica de dicha ¿realidad? Somos conscientes, y el debate está abierto, de la complejidad de las causas y de las consecuencias que los movimientos migratorios producen en las personas que los padecen: sueños o deseos, síndrome de Ulises, inadaptaciones, engaños, aptitudes racistas... Y, por supuesto las diferentes percepciones que se tienen ante ellos. Aquella carcajada final que nos sugiere un encantamiento con el papel representado, es seguida de un gesto sereno y sobrio, presente, que más allá de la acción identificativa del cuerpo de la mujer como objeto adornado y de consumo, señala los peligros de esta falsa integración.

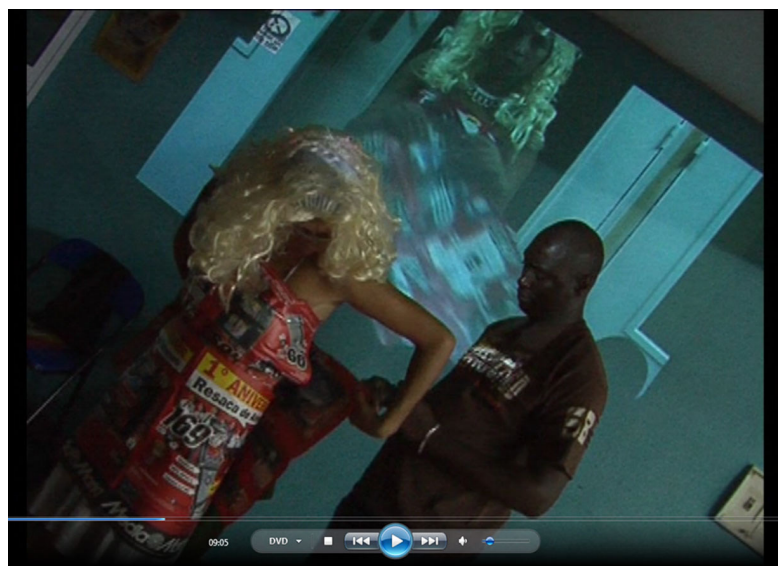

Figura 3. Proceso de integración, 2007 (Fotograma extraído del vídeo que se incluye en el catálogo Alterarte 07)

\subsection{Premio de arquitectura efímera para la construcción de un Peep Show}

La inmersión en las teorías feministas y su propia trayectoria de carácter social, llevan a Erika a desarrollar algunas actividades artísticas con el Comité de Apoyo a las Trabajadoras del sexo, CATS, de la Región de Murcia. Este trabajo marcará una serie de obras en las que reflexiona sobre las trabajadoras del sexo y la transexualidad y con las que propone un proceso de integración más. La igualdad de la mujer no se- 
ría posible sin admitir que su liberación está ligada a la emancipación de este colectivo que, según Gail Pheterson (1992) funciona para mantener el orden del patriarcado. Un paso para su visibilización es la propuesta de sacar su actividad al espacio público durante el día. Erika Trejo crea una estructura piramidal, en alusión al Prisma de la Prostitución de Gail Pheterson,

la prostitución es vista por la sociedad mediante un prisma donde lo refleja y lo magnifica, y mediante éste se miran modelos sociales estigmatizados de comportamiento de las personas, en este caso especificamente de las mujeres, comenta Erika.

Se trata de Premio de arquitectura efímera para la construcción de un Peep Show y una Barra Americana, (figura 4) que presenta en Alterarte 08, e instala en la plaza que da paso al Museo de Bellas Artes de Murcia. Una construcción presentada irónicamente como Premio de arquitectura efímera, quedaría incluida directamente en la cultura más elitista y exquisita. La artista contrasta con contundencia el interior del exterior, pero para participar en el juego de estos dos ambientes nos ofrece una fila de atrayentes mirillas, minúsculos agujeros para cotillear qué es lo que sucede tras este extraño premio de arquitectura.

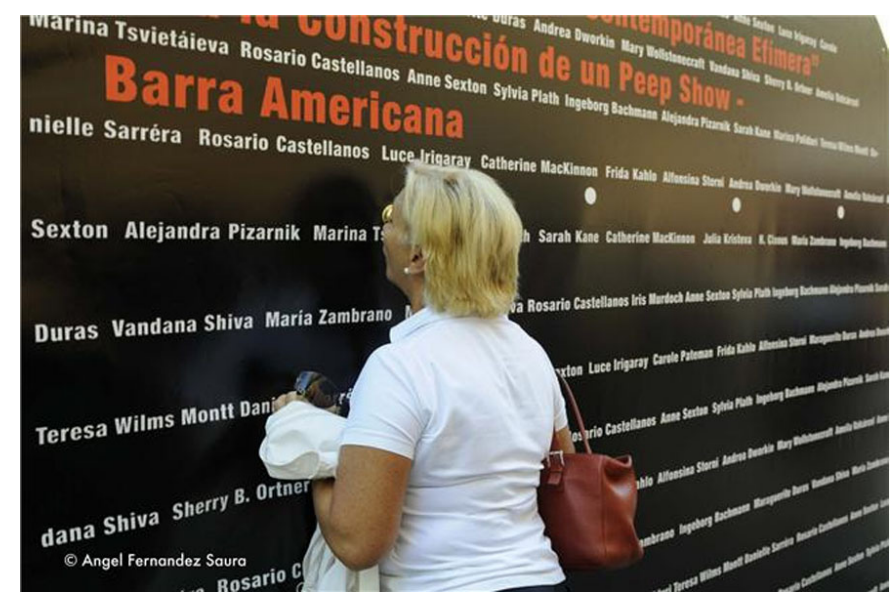

Figura 4. Premio de arquitectura efímera para la construcción de un Peep Show y una Barra Americana. (Fotografía extraída del catálogo Alterarte 08)

Fuera, uno de los lados retiene nuestra mirada ante varias fotografías de la industria del sexo donde participan activamente hombres y mujeres, denunciando los movimientos migratorios propiciados por este comercio; una pared blanca invita al público a su propia reflexión y en la tercera, una trama saturada de nombres de autoras dan la espalda a esta realidad.

El espectador o espectadora podrá observar un Peep Show interpretado por una mujer y un hombre, un baile erótico de cuerpos semidesnudos, 
un espectáculo erótico a plena luz del día, una revalorización de la prostitución y ésta como flujo migratorio femenino y masculino, dos latinoamericanos ofreciendo un servicio sexual, tan común en este país, puntualiza Erika.

En este sentido habría que recordar que

pocas son en el presente las mujeres españolas abocadas a la prostitución por vulnerabilidad o exclusión social. La realidad es que, cuando en una sociedad aumentan los espacios de igualdad y el nivel de vida, disminuye drásticamente el número de mujeres del propio país que se dedica a la prostitución. (Valcarcel, Sau, Amorós, Gisbert, Cobo, Montalbán y Miyares, 2011)

La conquista de la igualdad va ligada a la inclusión social de este colectivo, cuya carencia de regularización institucional y ambigüedad de la normativa favorece el tráfico y la explotación y "afecta normalmente a importantes factores definitorios de la situación laboral del trabajador", en este caso sobre todo de trabajadoras (Malgeseni, 2006:5)

De nuevo nos hallamos ante una ruptura temporal y espacial como método de acceso a esa lectura crítica propuesta por la artista, una actividad habitualmente nocturna es desarrollada durante el día pero, así mismo es trasladada de los márgenes culturales a la fachada del mausoleo de las Bellas Artes. La mirada invitada para la ocasión es la del transeúnte, pero también la del visitante del museo y la de estas autoras feministas que contemplan otra realidad marginal: las prostitutas, concepto que podríamos transformar si se les reconociera como trabajadoras de pleno derecho que "según ellas, pasa prioritariamente por el acceso a la seguridad social y a la jubilación de las que, como tales, están excluidas". (Malgeseni, 2006:7)

\subsection{In situ}

2008 cierra con 72 mujeres asesinadas. El peor año para la violencia de género. El 44,3\% de las mujeres asesinadas era inmigrante. Aido: "Estos datos ponen de manifiesto que el camino es largo, duro y dificil". En el 60,9\% de los casos, seguían manteniendo una relación con su asesino. Mucientes (2008)

Volvamos a nuestros mercados y desde ellos regresemos a nuestros hogares. No son ahora las tareas domésticas las mercancías para intercambiar en su discurso, sino la violencia ejercida sobre la mujer en este ámbito. Las noticias nos revelan los hechos evidentes, los más trágicos y sus estadísticas. Pero existe lo que Betty Friedan detectó y llamó: "el problema que no tiene nombre". Tras un estudio realizado a mujeres anglosajonas afirma que éstas sienten una gran insatisfacción con su vida provocada por todas las estructuras de poder que la comprimen y anulan sus necesidades. La libertad de hallar su propia identidad se ve acosada y bombardeada por un modelo de mujer-esposa-ama de casa sin proyectos propios, cuya felicidad está en la sumisión, la pasividad sexual y la crianza de sus hijos (1974). "En este sentido In situ es una pieza que como obra de arte intenta saltar de lo doméstico repetitivo, natural 
y pasivo, a lo público creador y científico con esos mismos elementos de pasividad asignados, reivindicando lo privado vinculado intrínsecamente a lo femenino, de lo popular a la alta cultura" señala Erika Trejo.

In situ (figura 5) se presenta como performance e instalación de la serie Dibon's, los carritos de la compra (usados principalmente en países capitalistas) y el vídeo de la acción llevada a cabo con ellos. La intención es llegar al mayor número de público y ejercer el efecto social que se pretende. Ante las trágicas noticias de violencia de género la artista se cuestiona: "¿Qué sucedería si invirtiéramos el orden de los hechos? ¿Si la violencia la ejerciesen las mujeres sobre los hombres? ¿Cómo actuarían los hombres ante estos hechos?, y la ley ¿cómo actuaría?" Para ella, el postfeminismo se propone cambiar los conceptos de pasividad y victimización del género femenino con estas preguntas que Erika retoma como base conceptual en Los Dibon's: recortes de prensa modificados en los que podemos leer cómo los asesinos se cambian por asesinas, dándonos esa otra perspectiva de la tragedia.

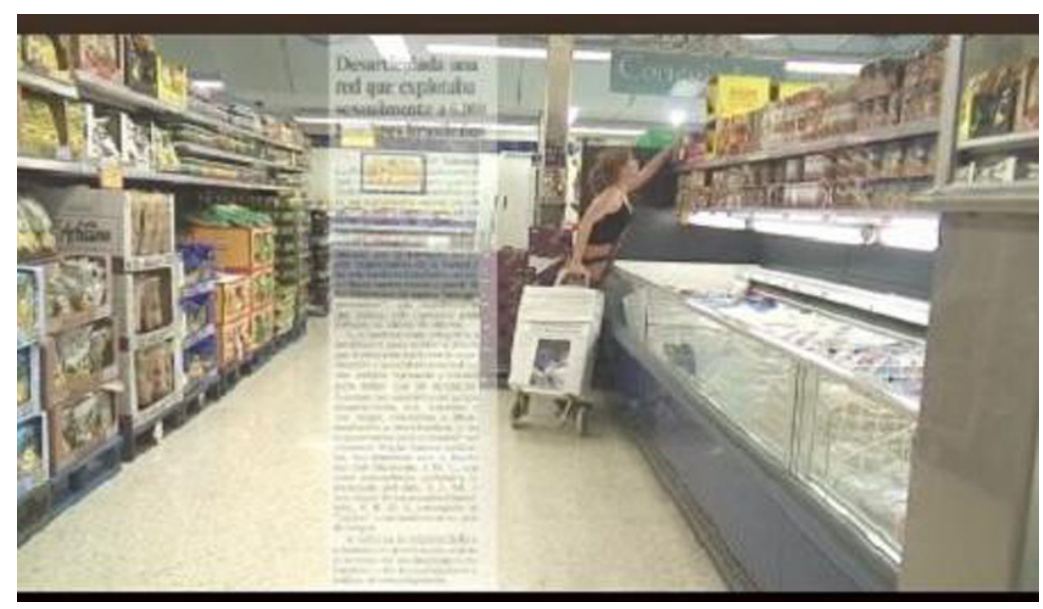

Figura 5. In situ.2008. Fotograma. (Imagen cedida por la artista)

La performance, posteriormente proyectada en la instalación, tiene como protagonistas a diez carritos de la compra. Esta cesta con ruedas no es fácil acarrearla por la ciudad, su peso, las aceras y los coches hacen que nuestros cuerpos reproduzcan los movimientos cenestésicos de un baile aprendido que dibuja los recorridos habituales un día tras otro. Un objeto tan pasivo, que se mueve a merced de su función por el espacio público pero que es arrinconado y permanece oculto en el espacio privado, ¿nos suena de algo? En la acción, el cuerpo sobreviene portador y difusor de esa violencia. Erika describe la obra como

una reivindicación de los trabajos domésticos, infravalorados ahora, y por lo tanto una reivindicación ante la violencia de género. Llevar a la sociedad la información in situ, esto es, en mercados que es un sitio femenino y otros que no lo son tanto, como quioskos, jardines y librerías. 


\subsection{Cruela}

Del carrito de la compra al cochecito de bebé para denunciar las violencias del ámbito doméstico en las que de un modo u otro se ve involucrada la mujer. Su cuerpo, una vez más, rompe los criterios ortodoxos del arte y de un ser modelo deviene a un ser acción. Se pasea por las calles de la ciudad ejerciendo sus funciones femeninas, la polémica ahora se asienta en la crianza y cuidado de hijas e hijos. La sociedad patriarcal ha especializado a las mujeres en la maternidad y ha diseñado el entramado de símbolos, mitos y arquetipos para que sea valorada como una tarea inferior. Pero la maternidad implica

la reproducción de la sociedad (los sujetos, las identidades, las relaciones, las instituciones) y de la cultura (la lengua, las concepciones del mundo y de la vida, las normas, las mentalidades, el pensamiento simbólico, los afectos y el poder) (Barbosa, 2008:123)

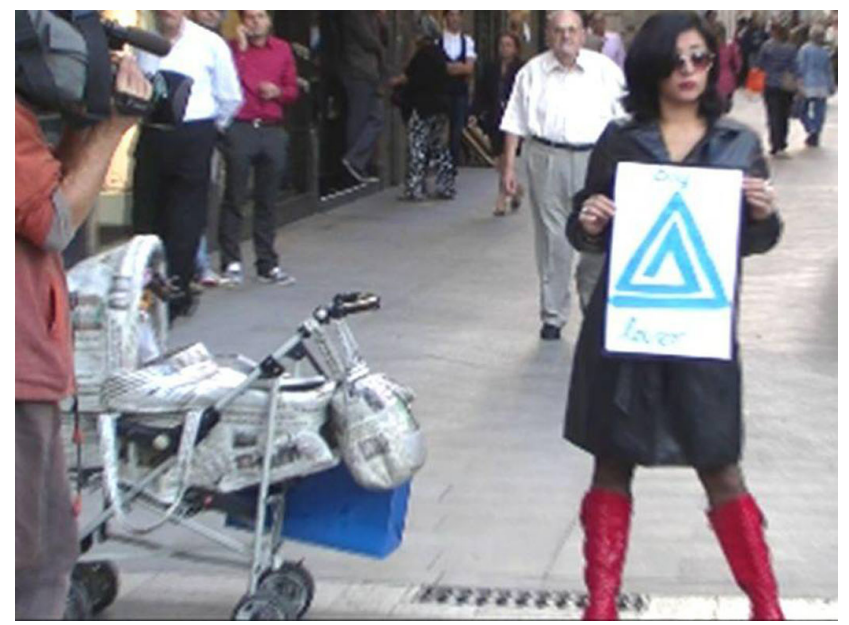

Figura 6. Cruela, Festival Alterarte, 2009 (Imagen cedida por la artista)

Para Erika ésta es una pieza que "habla desde la maternidad y desde la responsabilidad social". Cruela (Figura 6) es una mujer mala que lleva al extremo la permisivilidad de los abusos a menores que se comenten en el ámbito doméstico. La madre, por miedo a represalias o por amenazas, silencia esta violencia, volviéndose contra si misma. En los países más pobres, en los que la mujer asume la labor de cuidadora, es donde mayoritariamente sucede el tráfico sexual infantil. Es una obra que tenía pensada desde que nació su hija, al verla en el cochecito pensó cómo abordar la pederastia desde la representación y sobre todo desde su ser madre. Así, forró el carrito con noticias que aluden a dicha violencia. La artista se cuestiona su responsabilidad vestida con gabardina negra y altas botas rojas, a modo de mujer fatal, e invade una calle céntrica y comercial de la ciudad de Murcia (acción presentada en el Festival Alterarte 09). Es la representación del 
dramatismo de la existencia cotidiana de su ser mujer, vivido dentro de una sociedad intolerante que violenta a las mujeres, imponiéndoles papeles enajenantes que las embrutecen y niegan en su condición humana. (Barbosa, 2008:121)

Evidentemente con Cruela, Erika Trejo denuncia el destino de aquellas madres doblemente violentadas, pero así mismo cuestiona las imágenes arquetípicas de la maternidad, tal como hicieran el Grupo Polvo de Gallina Negra en su Proyecto visual ¡Madres! en 1988. Las dos componentes del grupo, Maris Bustamente y Mónica Mayer, asumieron su maternidad como obra plástica y abordaron, con gran versatilidad de medios, humor e ironía, "las mas controvertidas cuestiones de la compleja problemática femenina” (Barbosa, 2008:122)

\subsection{Plebiscito reproductivo}

Aparte de poner en duda la responsabilidad que implica la maternidad en la sociedad patriarcal, deberíamos preguntarnos si la mujer posee la decisión sobre su posibilidad. Erika se lo cuestiona en Plebiscito reproductivo, (figura 7) (Fundación García Jiménez, Murcia, 2009). Recurre a una triple proyección para situarnos en el centro de este debate democrático. No nos da una respuesta sobre su propia opinión y esto nos instala directamente ante una inquietante posición. Las imágenes van alternándose en estas proyecciones. Sobre un vientre en estado avanzado de embarazo ha escrito con letras rojas la frase de Simone de Beauvoir, "La reproducción supone una mera repetición de la vida", mientras en los demás vídeos otras mujeres nos cuentan sus experiencias en la decisión sobre su maternidad: "No tenía economía, ni a mi madre, ni siquiera mi pareja me apoyaba", "No está bien (el aborto), la vida es un principio, el único que da la vida es Dios y es el único que la puede quitar".

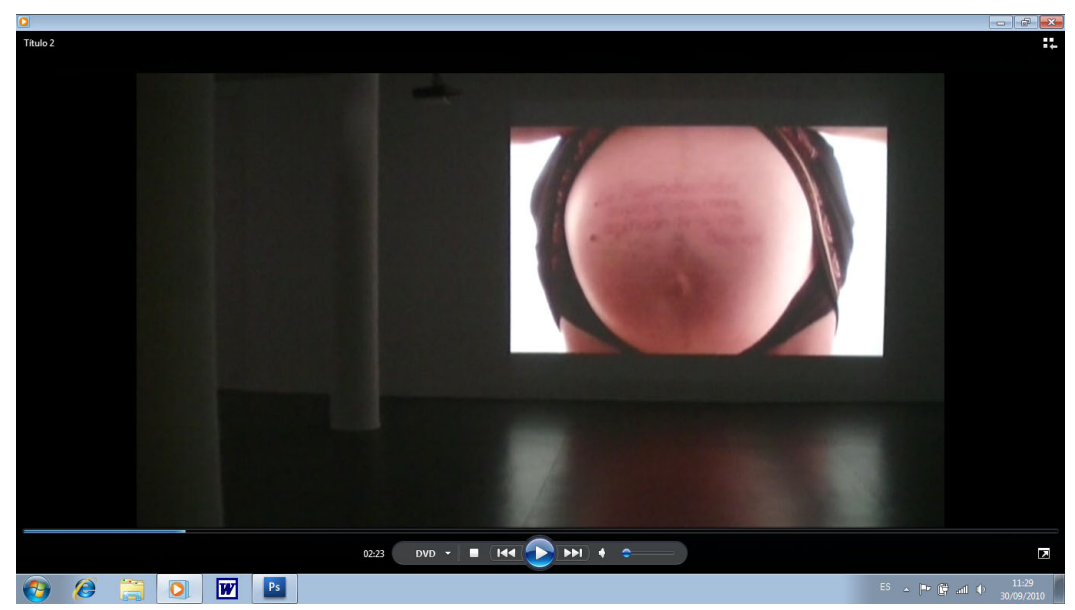

Figura 7. Plebiscito reproductivo, 2009. (Imagen extraída del video que acompaña al catálogo de la exposición) 
Es una obra absolutamente enunciativa, pero que una vez más recurre a la dislocación temporal y espacial para incitarnos a la reflexión. La imagen de la mujer se exhibe fragmentada, unas veces habla serenamente sentada frente a la cámara, dirigiéndose directamente al espectador o espectadora, en ocasiones la mirada es más perdida, y en las más inquietantes es sólo la nuestra, sin reflejo ya que sus cabezas han sido ignoradas. Antepone de este modo la presencia de la palabra como herramienta de debate sobre la reproducción. Si la maternidad ha definido al ser mujer, ¿será la conquista de la libertad en su decisión de ser o no madre la que la libere de los lastres impuestos por la sociedad patriarcal? Así el debate feminista se instala en la vindicación de la libertad, "en el núcleo de la igualdad, la libertad sería previa", nos expone Amelia Valcárcel (1997:64)

\subsection{Integración de sabores}

El último trabajo que comentaremos es Integración de sabores (figura 8) (Auditorio del Espacio Molinos del Río-Caballerizas, 2010). Un vídeo en el que una vez más parte de su condición de mujer inmigrante, pero que ahonda en cómo se comparten las tradiciones culturales. "Pero esta obra -comenta Erika- no es una revolución como las de las feministas que rompían el palo de la escoba, sino una enunciación." Una serie de mujeres provenientes de diferentes países (Ecuador, Bolivia, Ucrania, Marruecos e incluso de España) nos explican cómo elaboran sus platos más tradicionales cada una en su cocina, un gran encuentro de expresión de la riqueza y la diversidad cultural de los platos típicos.

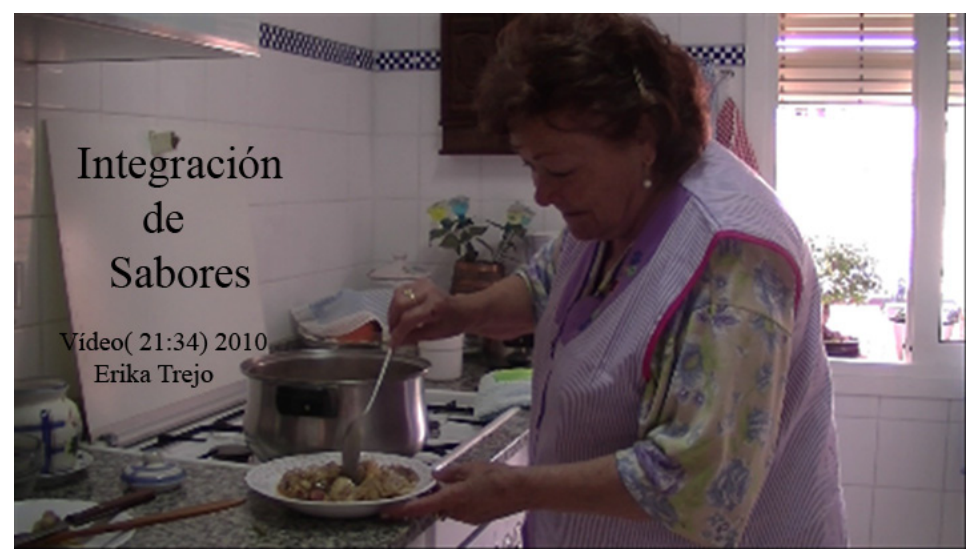

Figura 8. Integración de sabores. 2010. (Imagen cedida por la artista)

Las mujeres, al ser las encargadas de lo privado, hacen esta trenza de culturas en este vídeo, que intenta quitar el velo de lo privado, haciendo un acto performativo que al ser pronunciado realiza cierta acción y ejerce un poder vinculante, en palabras de Kate Millett, desde uno de los actos menos reconocidos ante la sociedad, uno de los trabajos de la mujer: cocinar para la familia. (Trejo, 2010) 
Ya no nos muestra una desvalorización de las tareas del hogar, como sucedía en Cosas de mujeres, tampoco es un obra cargada de metáforas y símbolos como aconteciera en la performance de Maris Bustameante, Las amas de casa de 1983, en la que aparece con diferentes mandiles de cuyos bolsillos va extrayendo objetos de cocina como si fuese una maga. Pero si algo comparten las tres es su intencionalidad para, como afirma Bustamante ante su obra, "tratar de rescatar y valorar el trabajo del ama de casa, que en general es un trabajo perdido que no tiene reconocimiento" (Barbosa, 2008:66)

Estas tareas ahora se dignifican, se desenvuelven con gran seriedad, se saborean, son labores que surgen desde el conocimiento para ser enunciadas. Es el universo simbólico femenino como constituyente y generador de cultura que toma lugar en la representación accediendo a un mundo compartido.

Erika propone una relectura del feminismo ya que asevera que

en un momento nos perdimos, el sujetador sí se quemó, pero realmente el producto que hemos conseguido no es satisfactorio, ni con el hombre, ni con los hijos, ni como mujer. No somos capaces de ir a lo interno, el exterior está muy bien, pero hemos descuidado el ámbito privado.

La cotidianidad de este acto y su performatividad, se hace posible cuando ella, cámara en mano, se nos hace presente y nos acerca a estas mujeres en un tu a tu, porque el diálogo que surge de la puesta en escena nos invita a tomar tres posiciones: el de la mujer que cocina, el de la artista, de la que en ocasiones oímos la voz, y el nuestro propio.

Es así que podemos reconocer en este trabajo que las mujeres "compartimos una posición genérica y una voluntad de abolir sus aspectos degradantes" (Irigaray, 1992:79) y que "concepciones agregativas tendrán muchas más dificultades en colocar barreras a tal libertad" (Valcárcel, 1997:87)

\section{Conclusiones}

El discurso cronológico en este punto y aparte, toma un giro de bucle para remitirnos al principio, y comprobar que efectivamente la obra de Erika parte de los mismos grupos de mujeres, porque este es el lugar para acceder a la experiencia y análisis de la propia realidad y su contexto. Como ella misma dice: "partir de ser mujer, madre e inmigrante". Una triada de adjetivos que han sido base de este intenso trabajo artístico, dirigiéndose con valentía a un público tradicional, y que nos ha mostrado la evolución de una propuesta subversiva entre la denuncia y la enunciación.

Este paso, de la denuncia a la enunciación, se sucede así mismo en un cambio de registro. Si atendemos a las primeras obras comentadas, su presencia en las calles abre una brecha en la representación tradicional de la sociedad conservadora que deja al margen los problemas sociales de las mujeres y aún más allá si éstos atañen a culturas ajenas. Compartir el espacio público con la acción es intercambiar sensaciones, movilizar conciencias y estimular reflexiones. El continuun realidad-ficción nos permite entrar y salir del mundo simbólico al real, y viceversa, para percibir que am- 
bos conspiran diseñando las estructuras de poder que Erika cuestiona en su discurso. Aquí su cuerpo es metáfora de experiencias plurales y comunes que se ejemplifican en una sola historia.

En las dos últimas, el cuerpo de Erika ha desaparecido de la representación, sólo su voz se hace perceptiva en las entrevistas con las mujeres. Lejos queda la dramatización directa en la calle. Erika asume el vídeo como herramienta discursiva, una técnica expresiva mucho más institucionalizada que el performance y que la artista introduce en salas de arte. Se nos sitúa en un espacio reflexivo en el que podemos acomodarnos para comprobar que aquellas mujeres que realizan la acción son cada una de ellas individualidades, del mismo modo que lo somos cada una de nosotras. Ante estas acciones entendemos la aportación de Erika Trejo como la continuidad del trabajo de las artistas feministas pioneras en México que representaron

su identidad en el arte, desde la autorrepresentación, rechazando y desenmascarando la lógica de la mirada masculina, que fabrica estereotipos femeninos ajenos a la identidad de las mujeres reales. (Barbosa, 2008:27)

y que influyeron en la construcción de una nueva cultura crítica con los estereotipos de género.

El Grupo Polvo de Gallina Negra nacía con una clara definición de objetivos, Erika conviene en destacar el tercero de ellos para definir estas prácticas artísticas:

Crear imágenes a partir de la experiencia de ser mujer en un sistema patriarcal, basadas en una perspectiva feminista y con miras a ir transformando el mundo visual para así alterar la realidad" (Mayer, 1999)

Porque no cabe duda que el universo simbólico de la mujer es gestionado en un círculo cerrado para su mejor control y que prácticas como éstas estimulan el cambio en los modos de vernos y posicionarnos en el mundo.

\section{Financiación}

Este trabajo es resultado del proyecto de investigación 08694/PHCS/08 financiado con cargo al Programa de Generación de Conocimiento Científico de Excelencia de la Fundación Séneca-Agencia de Ciencia y Tecnología de la Región de Murcia en el marco PCTRM 2007-10.

\section{Referencias}

Alcaide, A. 2001: Estéticas migratorias: conexiones entre el videoarte y la diáspora femenina. Revista Icono 14. Año 9. Vol 1. 67-90. Consultada en www.icono14. net 
Alterarte 06. 2006: Murcia: Instituto de la Juventud de la Región de Murcia. Consejería de Cultura, Juventud y Deportes.

Alterarte 07. 2007: Murcia: Instituto de la Juventud de la Región de Murcia. Consejería de Cultura, Juventud y Deportes.

Barbosa, A. 2008: Arte feminista en los ochenta en México. Una perspectiva de gérnero. México: Casa Juan Pablos. Universidad Autónoma del Estado de Morelos.

Besalier, H. 1993: Reflexiones sobre el fenómeno de la performance. En Gloria Picazo (coord.), Estudios de performance, (P. 134) Sevilla: Centro Andaluz de Teatro.

Blancarte, R., González, J.L. Y Casillas, R. 1993: La influencia de las religiones cristianas. En Bonfil Batalla, Guillermo (comp). Simbiosis de culturas: los inmigrantes y su cultura en México. (PP 548-554) México: Fondo de Cultura Económica.

http://dramaturgiasrurales.blogspot.com/2008/06/sin-los-indigenas-soy-nada.html Friedan, B. 1974: La mistica de la feminidad. Madrid: Ediciones Júcar.

Gaspar Verdú, V. 2006: El compromiso social del teatro de Brecht. En Blas Arroyo, Casanova Avalos y Velando Casanova (Eds) Discurso y sociedad: contribuciones al estudio de la lengua en contexto social. Castellón de la Plana: Publicaciones Universidad Jaime I.

Géneros???. 2008:Murcia: Centro Párraga

Guash, A.M. 2000: El arte último del siglo XX. Del posminimalismo a lo multicultural. Madrid: Alianza Forma.

Herrera Gomez, C. 2011: Más allá de las etiquetas. Nafarroa Txalaparta.

Irigaray, L. 1992: Yo, tú, nosotras. Madrid. Ediciones Cátedra.

Malgeseni, G. 2006: Impacto de una posible normalizacion profesional de la prostitución en la viabilidad y sostenibilidad futura del sistema de pensiones de protección social. Ministerio de Trabajo y Asuntos Sociales.Consultado en http:// www.seg-social.es/prdi00/groups/public/documents/binario/51873.pdf

Mayer, M. 1999: De cómo un buen día me di cuenta que yo sin el feminismo, no puedo vivir. N.Paradoxa, Número 8. Consultado en http://pintomiraya.com/es/ monica/textos-monica/51.html

Mohanty, C.T. 2008: De vuelta a "Bajo los ojos de Occidente": la solidaridad feminista a través de las luchas anticapitalistas. En Suarez Navaz, Liliana y Hernández, Rosalía Aída (eds) Descolonizando el feminismo. Teoría y prácticas desde los márgenes. (Págs 407-464). Madrid. Ediciones Cátedra.

Mucientes, E. (2008, 30 de diciembre) El mundo digital. http://www.elmundo.es/ elmundo/2008/12/30/espana/1230637976.html

Pheterson, G. 1992: Nosotras, las putas. Madrid. Editorial Talasa, S.L.

Trejo, E. 2009: Plebiscito reproductivo. Murcia: Fundación García Jiménez.

Trejo, E. 2010:. Folleto informativo de la exposición Integración de sabores. Murcia: Auditorio del Espacio Molinos del Río. Caballerizas. 
Valcarcel, A., Sau, V., Amorós,C., Gisbert, T., Cobo, R., Montalbán, I. Y Miyares, A. "Vulnerabilidad, marginación y pobreza son las causas que llevan a la prostitución, no sus consecuencias."

http://prostitucion-visionobjetiva.blogspot.com/2011/01/1a-prostitucion-es-unmodo-de-vida.html

Valcárcel, A. 1997: La política de las mujeres. Madrid: Ediciones Cátedra. 